\title{
www.czasopisma.pan.pl \\ Characterization of Coatings on Grey Cast Iron Fabricated by Hot-dipping in Pure Al, AlSi11 and AITi5 Alloys
}

\author{
R. Mola ${ }^{\text {a, }}$, T. Bucki ${ }^{\text {a }}$, K. Wcisło ${ }^{\text {b }}$ \\ ${ }^{a}$ Department of Applied Computer Science and Armament Engineering, Faculty of Mechatronics and Machine Design, \\ Kielce University of Technology, Al. 1000-lecia P.P. 7, 25-314 Kielce, Poland \\ ${ }^{\mathrm{b}}$ Students of Mechanical Engineering, \\ *Corresponding author. E-mail address: rmola@tu.kielce.pl
}

Received 24.06.2013; accepted in revised form 02.09.2013

\begin{abstract}
Flake graphite cast iron was hot-dip coated with pure aluminium or aluminium alloys (AlSi11 and AlTi5). The study aimed at determining the influence of bath composition on the thickness, microstructure and phase composition of the coatings. The analysis was conducted by means of an optical microscope and a scanning electron microscope with an EDS spectrometer. It was found that the overall thickness of a coating was greatly dependent on the chemical composition of a bath. The coatings consisted of an outer layer and an inner intermetallic layer, the latter with two zones and dispersed graphite. In all the cases considered, the zone in the inner intermetallic layer adjacent to the cast iron substrate contained the $\mathrm{Al}_{5} \mathrm{Fe}_{2}$ phase with small amount of silicon; the interface between this phase and the cast iron substrate differed substantially, depending on the bath composition. In the coatings produced by hot-dipping in pure aluminium the zone adjacent to the outer layer had a composition similar to that produced from an $\mathrm{AlTi} 5$ bath, the $\mathrm{Al}_{3} \mathrm{Fe}$ phase was identified in this zone. The $\mathrm{Al}_{3} \mathrm{Fe}$ also contained silicon but its amount was lower than that in the $\mathrm{Al}_{5} \mathrm{Fe}_{2}$. In the coatings produced by hot-dipping in AlSil1, the zone adjacent to the outer layer contained the $\mathrm{Al}_{3} \mathrm{FeSi}$ phase. The analysis results showed that when AlSi11 alloy was applied, the growth mode of the inner layer changed from inwards to outwards. The interface between the $\mathrm{Al}_{5} \mathrm{Fe}_{2}$ phase and the cast iron substrate was flat and the zone of this phase was very thin. Locally, there were deep penetrations of the $\mathrm{Al}_{5} \mathrm{FeSi}$ phase into the outer layer, and the interface between this phase and the outer layer was irregular. Immersion in an AlTi5 bath caused that the inner intermetallic layer was thicker than when pure aluminium or AlSil1 alloy baths were used; also, some porosity was observed in this layer; and finally, the interface between the inner layer and the cast iron substrate was the most irregular.
\end{abstract}

Keywords: Hot-dip aluminizing, Flake graphite cast iron, Intermetallic phases, Microstructure

\section{Introduction}

Hot-dip aluminizing of steel and cast iron is a low cost technique widely used to improve their oxidation and corrosion resistance. The process can involve hot-dip coating either with pure aluminium or aluminium alloys. The kinetics of the coating process, as well as the thickness and structure of the coating depend on the following factors: the temperature and chemical composition of the bath, the holding time and the type and microstructure of the coating material [1-3]. The coating microstructure generally comprises an outer layer with a composition similar to that of the molten bath and an inner intermetallic layer, which is very hard and brittle. The basic 
mechanical, chemical and physical properties of the coating depend on the thickness and morphology of the intermetallic layer between the outer layer and the substrate. Many of the papers discussing the process of hot-dip coating with aluminium and aluminium alloys focus on the reaction between the base material and the bath, especially the effect of the chemical composition of the bath on the formation of the intermetallic layer. An important finding is that the formation of the intermetallic layer can be greatly retarded if silicon is added to the bath. The presence of silicon causes a reduction up to a few microns in the thickness of the diffusion layer [4-6].

In this study, grey cast iron was aluminized by hot-dip coating with commercially available pure aluminium and aluminium alloys (AlSi11 and AlTi5). The aim was to investigate the effect of the bath composition on the coating microstructure, thickness and chemical composition.

\section{Experimental details}

GJL200 pearlitic flake graphite cast iron was used as the substrate material. The material microstructure is presented in Fig.1.

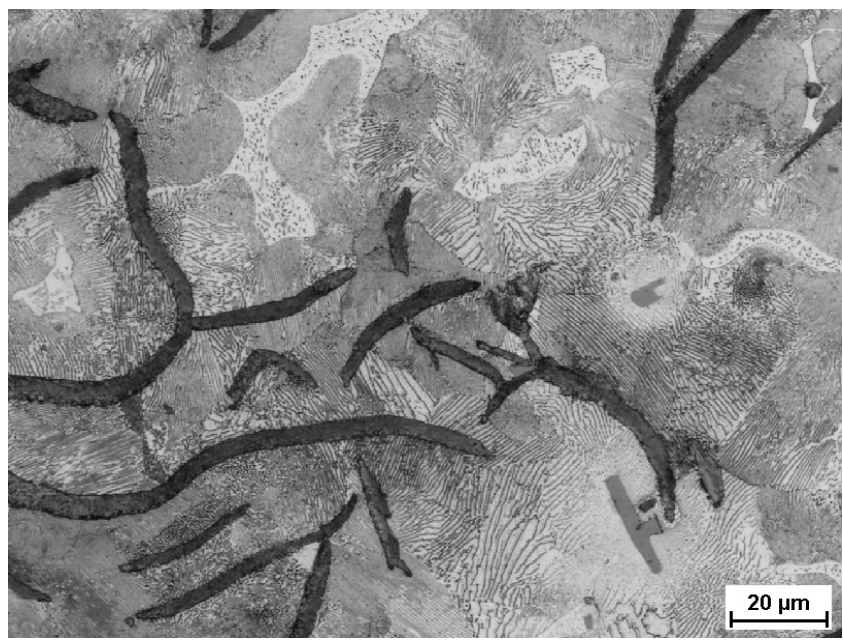

Fig. 1. An OM micrograph of the flake graphite cast iron (pearlitic matrix and graphite flakes)

Cuboid specimens $\left(30 \times 15 \times 10 \mathrm{~mm}^{3}\right)$ were prepared by cutting with a linear cutting machine, then grinding with 800 -grit paper and finally cleaning in ethanol. Hot dip aluminizing was performed under laboratory conditions using a Nabertherm melting furnace furnished with a graphite crucible. The specimens were immersed in a molten bath of commercially available pure aluminium (A1), AlSi11 or AlTi5 alloys at $750{ }^{\circ} \mathrm{C}$ for $20 \mathrm{~min}$. The chemical compositions of the aluminium alloys are given in Table 1.
Table 1.

Chemical composition of the alloys used for hot-dip aluminizing

\begin{tabular}{ccccccc}
\hline Alloy & \multicolumn{7}{c}{ Element (wt.\%) } \\
\cline { 2 - 7 } & $\mathrm{Si}$ & $\mathrm{Fe}$ & $\mathrm{Ti}$ & $\mathrm{Zn}$ & $\mathrm{Mn}$ & $\mathrm{Al}$ \\
\hline A1 & 0.15 & 0.3 & - & - & - & $\mathrm{Bal}$ \\
\hline AlSi11 & 11.8 & 0.8 & - & - & 0.3 & Bal \\
\hline AlTi5 & 0.28 & 0.44 & 4.74 & 0.1 & 0.07 & Bal \\
\hline
\end{tabular}

Then the specimens were sectioned and prepared for microscopic observations following standard metallographic methods. The microstructure analysis of the aluminized specimens was conducted by means of a Nikon ECLIPSE MA 200 optical microscope and a JEOL JSM-5400 scanning electron microscope. The chemical composition analysis was performed using an Oxford Instruments ISIS 300 energy dispersive X-ray spectrometer (EDS) attached to the SEM.

\section{Results and discussion}

\subsection{Hot dip coating with pure aluminium}

The microstructure of grey cast iron hot-dip coated with pure aluminium at $750{ }^{\circ} \mathrm{C}$ for $20 \mathrm{~min}$ is shown in Fig. 2. The coating consists of an outer layer about $240 \mu \mathrm{m}$ in thickness and a uniform inner layer nearly $40 \mu \mathrm{m}$ in thickness.

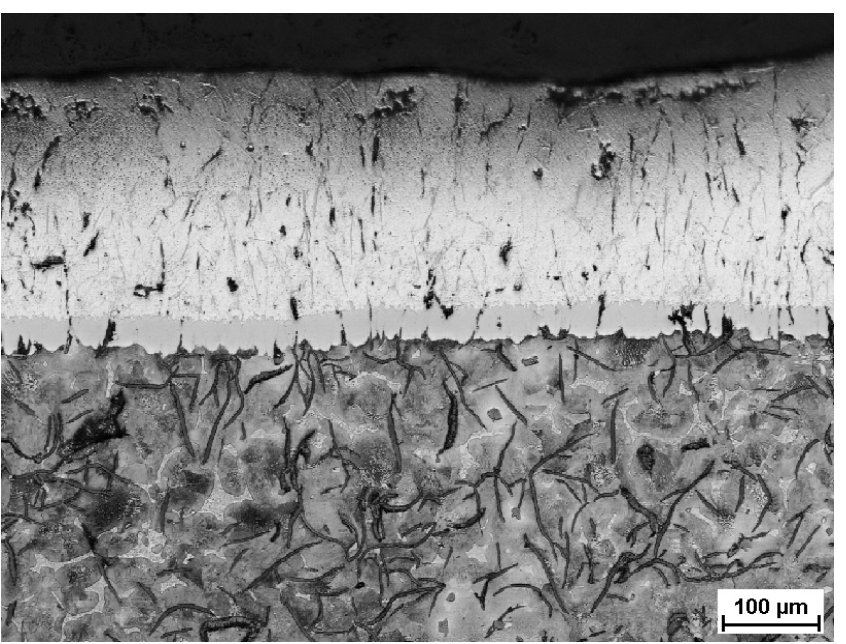

Fig. 2. An optical micrograph of graphite cast iron hot-dip coated with pure aluminium

An SEM image of the aluminized cast iron and the corresponding EDS spectra indicating the distributions of $\mathrm{C}, \mathrm{Al}$, $\mathrm{Si}$ and $\mathrm{Fe}$ along the index line are presented in Fig. 3. In the outer layer, the needle-like Fe-rich phase and flake graphite were dispersed. The inner layer contained aluminium and iron; some trapped flake graphite was also observed. 


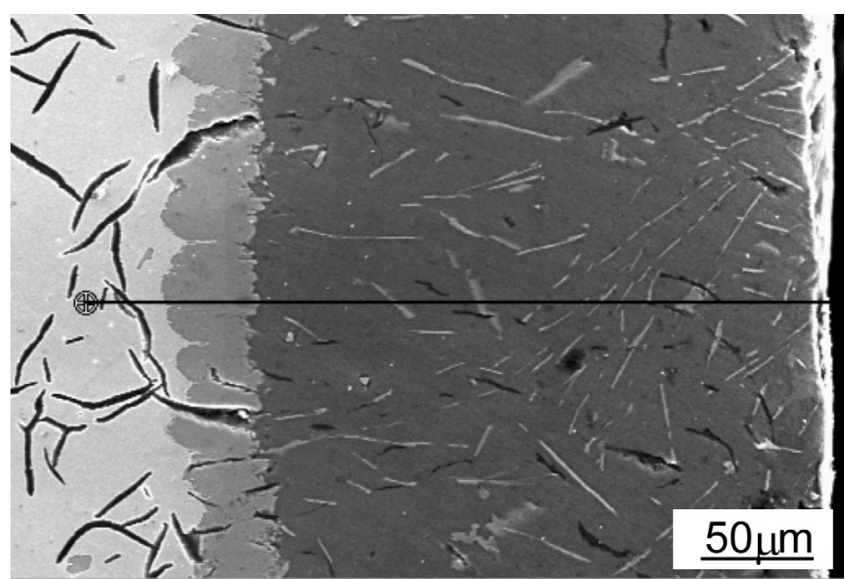

CKa, 99
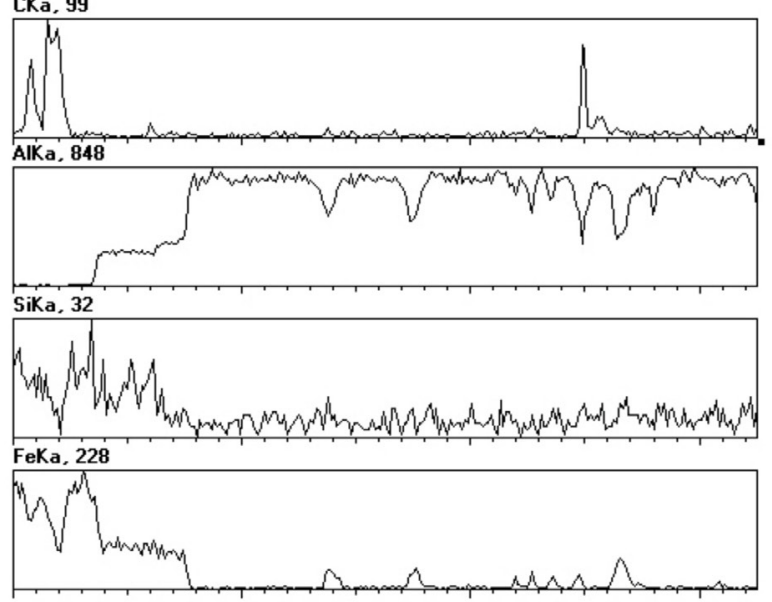

Fig. 3. A cross-sectional SEM micrograph of the cast iron specimen hot-dip coated with pure aluminium and the corresponding EDS spectra

Figure 4 shows a high magnification image of the inner layer with two zones: a thicker zone adjacent to the cast iron substrate and a thinner zone adjacent to the outer aluminium layer. The chemical composition analysis by EDS revealed that the thicker zone (marked A in Fig. 4) contained 71.50 at.\% Al, 25.75 at.\% Fe and 2.75 at.\% $\mathrm{Si}$, which corresponded to the $\mathrm{Al}_{5} \mathrm{Fe}_{2}$ phase with a small amount of $\mathrm{Si}$ in a solid solution. The presence of silicon in this zone was due to the presence of this element in the cast iron substrate. The composition of the thinner zone (marked B in Fig. 4) established through a point analysis was 79.51 at.\% $\mathrm{Al}, 19.62$ at. $\% \mathrm{Fe}$ and 0.87 at. $\% \mathrm{Si}$, which suggests the presence of the $\mathrm{Al}_{3} \mathrm{Fe}$ phase with the small content of silicon. Silicon atoms may replaced aluminium atoms in all the binary intermetallic phases of the $\mathrm{Fe}-\mathrm{Al}$ system. The solubility of silicon in the $\mathrm{AlFe}_{3}, \mathrm{Al}_{5} \mathrm{Fe}_{2}$ and $\mathrm{Al}_{3} \mathrm{Fe}$ ranged from 1 at.\% to 7 at.\%. [6,7].

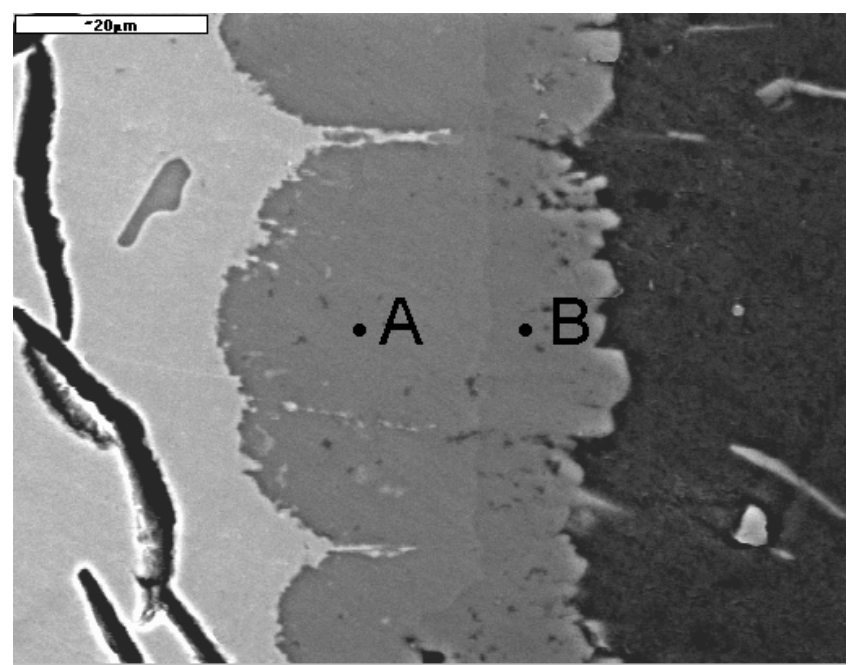

Fig. 4. An SEM micrograph of the reaction layer formed between cast iron and pure aluminium

The interface between the $\mathrm{Al}_{5} \mathrm{Fe}_{2}$ phase and the cast iron substrate exhibited irregular tongue-like morphology. A more regular interface was observed between the $\mathrm{Al}_{3} \mathrm{Fe}$ phase and the outer layer.

\subsection{Hot dip coating with AlSi11 alloy}

Figure 5 shows an optical micrograph of a cross-section of grey cast iron hot-dip coated with AlSil1 alloy at $750{ }^{\circ} \mathrm{C}$ for $20 \mathrm{~min}$. The overall thickness of the coating is about $380 \mu \mathrm{m}$.

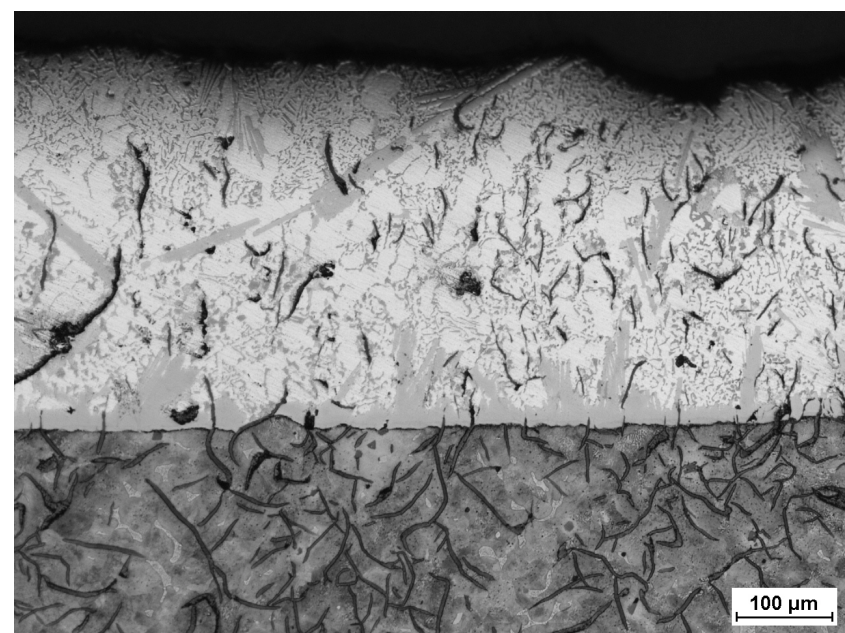

Fig. 5. An optical micrograph of graphite cast iron hot-dip coated with AlSil1 alloy

Figure 6 presents an SEM image and the corresponding EDS spectra illustrating the distribution of elements $(\mathrm{C}, \mathrm{Al}, \mathrm{Si}$ and $\mathrm{Fe})$ in the coating. Flake graphite precipitates and large Al-Fe-Si needle- and plate- shaped phases can be seen in the Al-Si outer layer. Microscopic observations revealed that the thickness of the inner intermetallic layer was not uniform. 

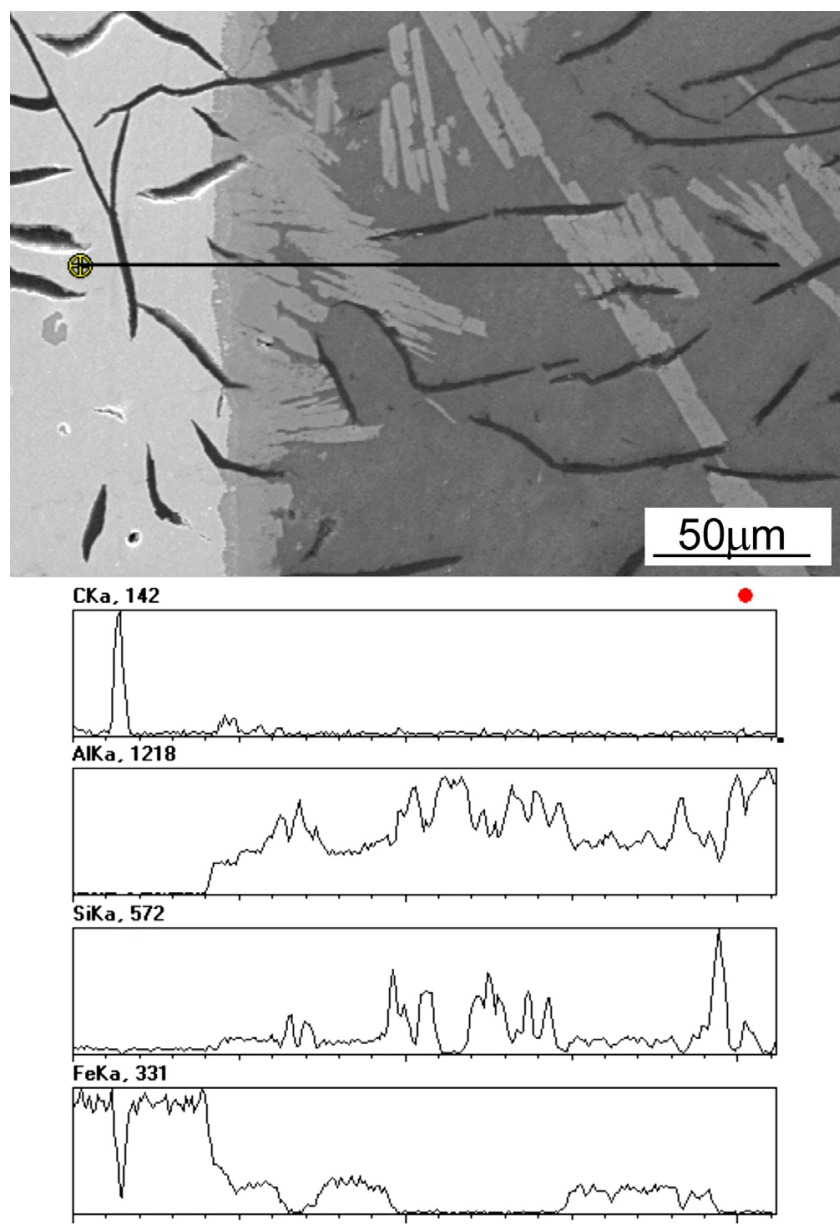

Fig. 6. A cross-sectional SEM micrograph of the cast iron hot-dip coated with AlSi11 alloy and the corresponding EDS spectra

A high magnification SEM image of the inner layer is presented in Fig. 7. In this layer, two zones can also be distinguished. The EDS analysis indicated that the content of the thin zone (marked A in Fig. 7), adjacent to the cast iron substrate, was 70.37 at. $\% \mathrm{Al}, 26.04$ at.\% Fe and 3.59 at.\% Si. It was similar to that of the $\mathrm{Al}_{5} \mathrm{Fe}_{2}$ phase. The amount of solid solution of silicon in this phase was higher, compared with that observed in a pure aluminium coating. The interface between the $\mathrm{Al}_{5} \mathrm{Fe}_{2}$ phase and the cast iron substrate was regular and nearly flat; the zone of this phase was much thinner than that produced from an aluminium bath. The thickness of the zone of the $\mathrm{Al}_{5} \mathrm{FeSi}$ phase adjacent to the outer layer was not uniform; locally, there were deep penetrations of the phase into the outer layer, making the interface irregular. The content of this zone (marked $\mathrm{C}$ in Fig. 7), i.e. 66.39 at.\% $\mathrm{Al}, 17.03$ at. $\% \mathrm{Si}$ and 16.58 at.\% $\mathrm{Fe}$, was similar to that of the $\mathrm{Al}_{5} \mathrm{FeSi}$ phase. The Al-Fe-Si phases randomly distributed in the Al-Si outer layer (marked D in Fig. 7) had similar compositions, i.e. 67.76 at.\% $\mathrm{Al}, 18.14$ at.\% $\mathrm{Si}$ and 14.10 at.\% Fe.

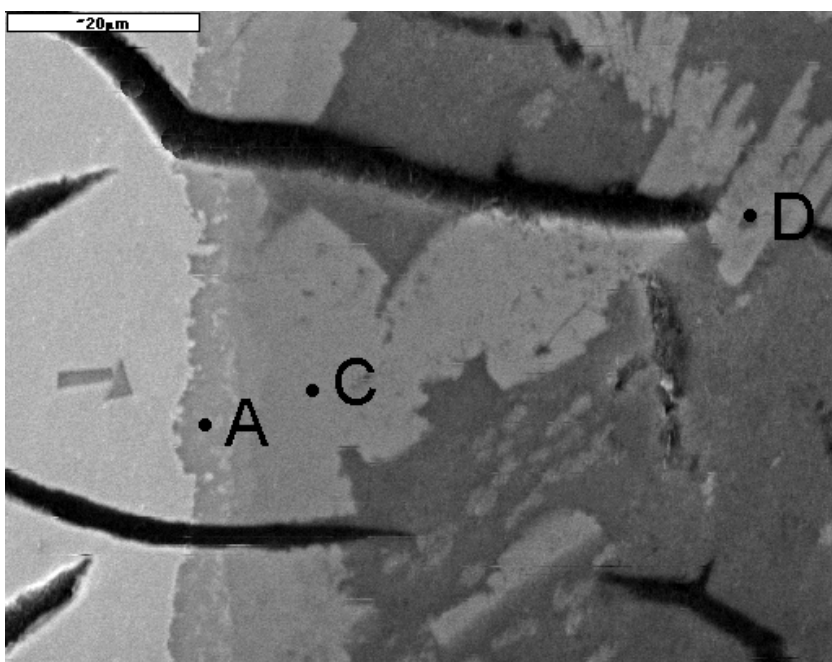

Fig. 7. An SEM micrograph of the reaction layer formed between cast iron and AlSil1 alloy

The presence of $\mathrm{Si}$ in a molten aluminium bath caused a reduction in the thickness of the $\mathrm{Al}_{5} \mathrm{Fe}_{2}$ zone. It is generally recognized that $\mathrm{Si}$ reduces the rate of diffusion of solid state $\mathrm{Al}$ in iron-based alloys, which may prevent the $\mathrm{Al}_{5} \mathrm{Fe}_{2}$ growth $[2,5,8]$. The addition of silicon into a molten aluminium bath changed the growth mode of the inner intermetallic layer from inwards to outwards. The analysis results confirmed that the inner intermetallic layer grows in the direction of the Al-Si outer layer.

\subsection{Hot dip coating with AlTi5 alloy}

The microstructure of cast iron aluminized in a bath of AlTi5 at a temperature of $750{ }^{\circ} \mathrm{C}$ for $20 \mathrm{~min}$ is shown in Fig. 8. The overall thickness of the coating was about $250 \mu \mathrm{m}$. It was similar to that produced from an pure aluminium bath; however, the inner layer was much thicker, in the range $50-100 \mu \mathrm{m}$.

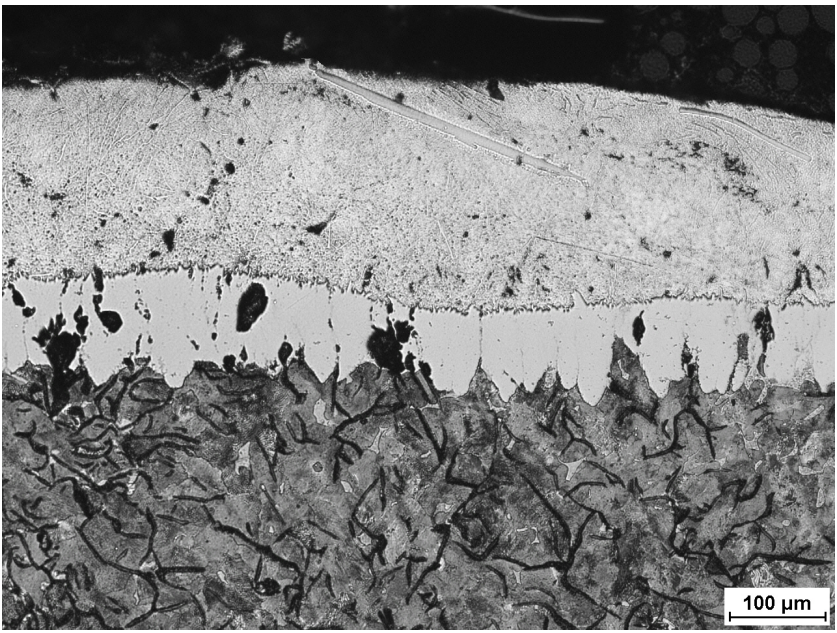

Fig. 8. An optical micrograph of graphite cast iron hot-dip coated with AlTi5 alloy 
The SEM images and the corresponding EDS spectra in Fig. 9 show distributions of $\mathrm{C}, \mathrm{Al}, \mathrm{Si}, \mathrm{Ti}$ and $\mathrm{Fe}$ in the coating. The inner layer was not free from defects; some pores were observed. In the outer layer, there were fine needle-shaped Fe-rich phases and single long needle-shaped Ti-rich phases. Moreover, the amount of flake graphite was smaller than that in the coatings discussed above.
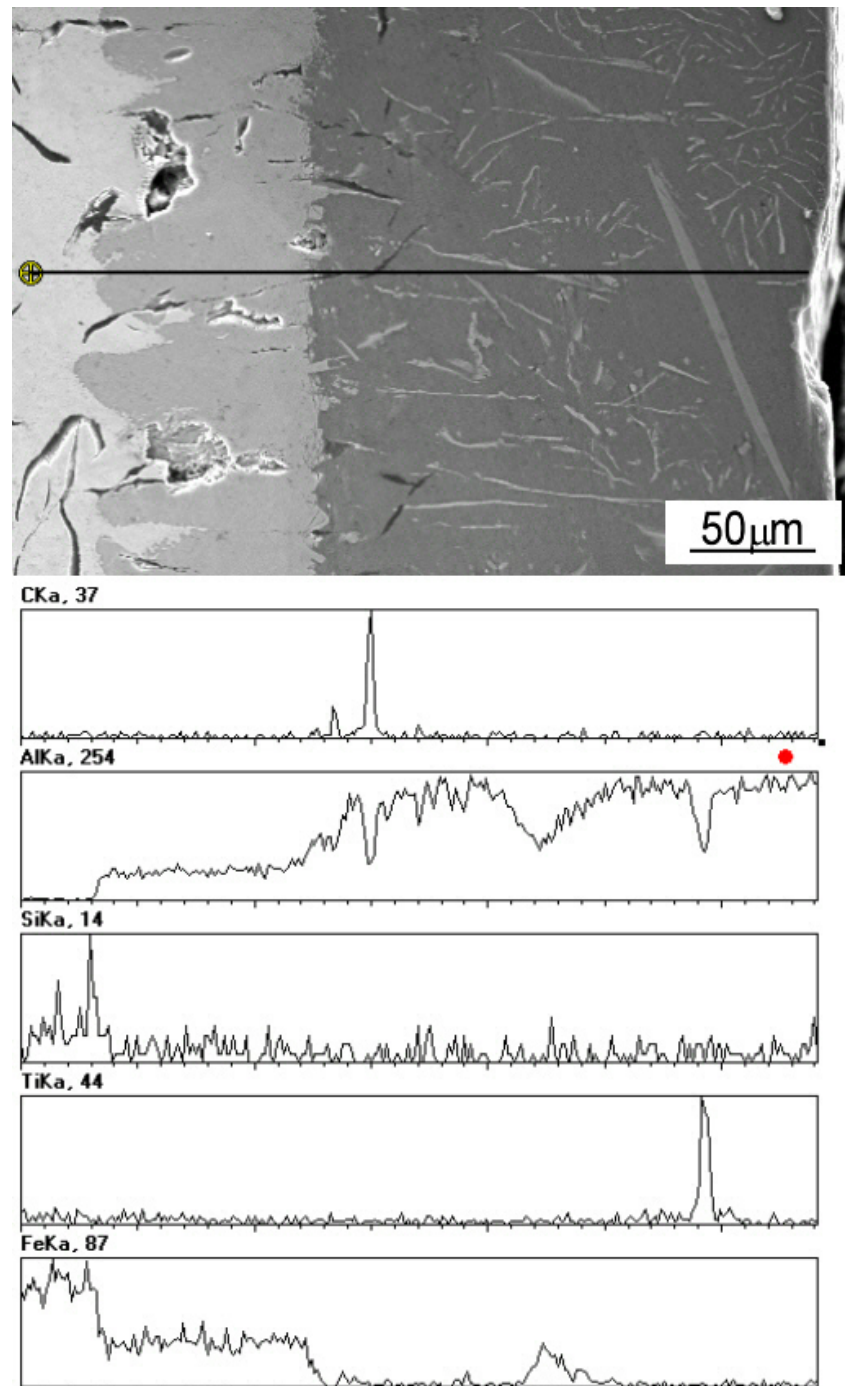

Fig. 9. A cross-sectional SEM micrograph of cast iron hot-dip coated with AlTi5 alloy and the corresponding EDS spectra

As can be seen from the high magnification image of the inner layer in Fig. 10, there are also two zones: a thick zone adjacent to the cast iron substrate (marked A in Fig. 10), containing 71.37 at.\% $\mathrm{Al}, 26.11$ at. $\% \mathrm{Fe}$ and 2.52 at. $\% \mathrm{Si}$, and a thin zone adjacent to the outer layer (marked B in Fig. 10) with 76.83 at.\% Al, 21.95 at.\% $\mathrm{Fe}$ and 1.22 at.\% $\mathrm{Si}$. The EDS analysis revealed that the inner layer contained $\mathrm{Al}_{5} \mathrm{Fe}_{2}$ and $\mathrm{Al}_{3} \mathrm{Fe}$ intermetallic phases. The interface between the $\mathrm{Al}_{5} \mathrm{Fe}_{2}$ phase and the cast iron substrate was irregular and exhibited a finger-like profile. The interface between the $\mathrm{Al}_{3} \mathrm{Fe}$ phase and the outer layer was flatter; however, some defragmentation of the $\mathrm{Al}_{5} \mathrm{Fe}_{2}$ phase was observed near the outer layer. The content of the single, long, needle-shaped Ti-rich phases (75.66 at.\% $\mathrm{Al}, 0.48$ at.\% $\mathrm{Si}$ and 23.86 at.\% Ti) present in the outer layer, which was determined through EDS point analysis, was similar to that of the $\mathrm{Al}_{3}$ Ti phase (Fig. 9). In the Al$\mathrm{Ti}$ outer layer, the concentration of $\mathrm{Ti}$ (wt.\%) in the matrix was $0.63 \%$.

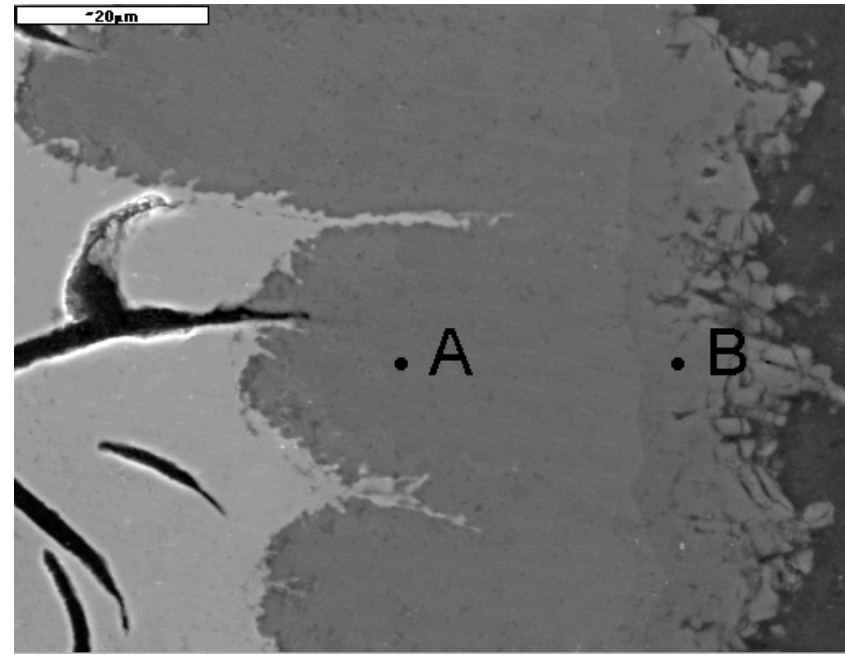

Fig. 10. An SEM micrograph of the reaction layer formed between cast iron and AlTi5 alloy

Comparing the three types of coatings, we can conclude that the coating produced from an AlTi5 bath had the thickest inner intermetallic layer and the most irregular interface between the inner layer and the cast iron substrate. Furthermore, the porosity observed in that layer was probably due to the reactions taking place between titanium in the molten metallic bath and the cast iron substrate during the aluminizing process.

\section{Conclusions}

The findings can be summarized as follows.

1. Flake graphite cast iron was hot-dip coated with pure aluminium or aluminium alloys (AlSi11 and AlTi5). The coating consisted of an outer layer, an inner intermetallic layer and dispersed flake graphite. The overall thickness of the coating was dependent on the composition of the bath. The aluminizing process was performed at the same parameters, i.e. a holding time of $20 \mathrm{~min}$ and a bath temperature of $750{ }^{\circ} \mathrm{C}$. The coatings produced by immersion in AlSil1 alloy were much thicker than those obtained by the application of pure aluminium or AlTi5 alloy.

2. The bath composition affected the thickness, morphology and the phase constitution of the inner intermetallic layer forming between the outer layer and the cast iron substrate.

3. When the process involved pure aluminium, the inner intermetallic layer about $40 \mu \mathrm{m}$ in thickness had two zones: a thick zone of the $\mathrm{Al}_{5} \mathrm{Fe}_{2}$ phase adjacent to the cast iron substrate and a thin zone of the $\mathrm{Al}_{3} \mathrm{Fe}$ phase adjacent to the 
outer layer. The interface between the $\mathrm{Al}_{5} \mathrm{Fe}_{2}$ phase and the substrate was irregular, showing tongue-like morphology; the interface between the $\mathrm{Al}_{3} \mathrm{Fe}$ phase and the outer layer, on the other hand, was regular.

4. The morphology of the inner layer changed considerably when the process was conducted in an AlSil1 alloy bath. The inner layer was also composed of two zones but the zone of the $\mathrm{Al}_{5} \mathrm{Fe}_{2}$ phase adjacent to the cast iron substrate was thin and the interface between this phase and the substrate was rather flat. The zone of the $\mathrm{Al}_{5} \mathrm{FeSi}$ phase adjacent to the Al-Si outer layer was irregular, with local deep penetrations into the outer layer. In such a case, the intermetallic layer grew towards the outer layer.

5. When the cast iron was hot-dip coated with AlTi5 alloy, the inner layer was composed of a zone of the $\mathrm{Al}_{5} \mathrm{Fe}_{2}$ phase and a zone of the $\mathrm{Al}_{3} \mathrm{Fe}$ phase. Some porosity was observed in the inner layer. The $\mathrm{Al}_{5} \mathrm{~F}_{2}$ phase adjacent to the cast iron grew into the substrate as finger-like crystals. The interface between this phase and the cast iron substrate was the most irregular compared with the other coatings. The interface between the $\mathrm{Al}_{3} \mathrm{Fe}$ phase and the $\mathrm{Al}$-Ti outer layer was more regular but the defragmentation of this phase was observed close to the outer layer.

\section{References}

[1] Cheng,W. J. \& Wang, C. J. (2011). Microstructural evolution of intermetallic layer in hot-dipped aluminide mild steel with silicon addition. Surf. Coat. Technol. 205, 4726-4731. DOI: 10.10.16/j.surfcoat.2011.04.061.

[2] Pietrowski, S. \& Szymczak, T. (2011). Theoretical basis of Al-Si coat crystallization on gray and nodular cast iron and making the layered items using it. Journal of Achievements in Materials and Manufacturing Engineering. 49(2), 421439.

[3] Pietrowski, S. \& Szymczak, T. (2006). The influence of selected technological elements on the structure of alphinizing coat on iron alloys. Archives of Foundry. 6(19), 251-266.

[4] Gembalski, S. (1969). Diffusion aluminizing of steel, cast iron, copper and titanium. Metal Science and Heat Treatment. 9(9), 646-651.

[5] Gierek, A. \& Bajka, L. (1976). Dip aluminized - properties and applications. Design Issues. 12, 356-360.

[6] Springer, H., Kostka, A., Payton, E. J., Raabe, D., KaysserPyzalla, A. \& Eggeler, G. (2011). On the formation and growth of intermetallic phases during interdiffusion between low-carbon steel and aluminium alloys. Acta Mater. 59, 1586-1600. DOI: 10.1016/j.actamat.2010.11.023.

[7] Maitra, T. \& Gupta, S. P. (2003). Intermetallic compound formation in Fe-Al-Si ternary system: Part II Mater. Charact. 49, 293-311. DOI: 10.1016/S1044-5803(03)00005-6.

[8] Lin, M. B., Wang, C. J. \& Volinsky, A. A. (2011). Isothermal and thermal cycling oxidation of hot-dip aluminide coating on flake/spheroidal graphite cast iron. Surf. Coat. Technol. 206, 1595-1599. DOI: 10.1016/j. surfcoat.2011.06.010 